University of Massachusetts Amherst

ScholarWorks@UMass Amherst

Chemistry Department Faculty Publication Series

Chemistry

2004

\title{
Element selective characterization of stability and reactivity of selenium species in selenized yeast
}

PC Uden

HT Boakye

C Kahakachchi

R Hafezi

P Nolibos

See next page for additional authors

Follow this and additional works at: https://scholarworks.umass.edu/chem_faculty_pubs

Part of the Chemistry Commons

\section{Recommended Citation}

Uden, PC; Boakye, HT; Kahakachchi, C; Hafezi, R; Nolibos, P; Block, E; Johnson, S; and Tyson, JF, "Element selective characterization of stability and reactivity of selenium species in selenized yeast" (2004). Journal of Analytical Atomic Spectrometry. 1027.

Retrieved from https://scholarworks.umass.edu/chem_faculty_pubs/1027 
Authors

PC Uden, HT Boakye, C Kahakachchi, R Hafezi, P Nolibos, E Block, S Johnson, and JF Tyson 


\title{
Element selective characterization of stability and reactivity of selenium species in selenized yeast
}

\author{
Peter C. Uden, ${ }^{* a}$ Harriet Totoe Boakye, ${ }^{a}$ Chethaka Kahakachchi, ${ }^{a}$ Rameh Hafezi, ${ }^{a}$ \\ Paula Nolibos, ${ }^{b}$ Eric Block, ${ }^{b}$ Sherida Johnson ${ }^{b}$ and Julian F. Tyson ${ }^{a}$ \\ ${ }^{a}$ Department of Chemistry, Lederle Graduate Research Tower A701, University of \\ Massachusetts, Amherst MA 01003-9336, USA \\ ${ }^{b}$ Department of Chemistry, SUNY-Albany, Albany NY 12222, USA
}

Received 1st July 2003, Accepted 15th September 2003

First published as an Advance Article on the web 13th October 2003

The concerted application of element specific atomic spectral detection for chromatographic eluent monitoring allows previously unexploited qualitative and quantitative analytical concepts to be developed for the determination of selenium species. Selenium speciation is vital in order to better understand its metabolism and biological significance in clinical chemistry, biology, toxicology, and nutrition. Fluoroacid ion pair HPLC with ICP-MS detection and GC derivatization with atomic emission detection (AED) together aid analysis and elucidation of reaction pathways of selenium compounds in high selenium enriched yeast, as used widely in nutritional and clinical cancer preventative studies. Comparisons between currently produced and archived selenized yeasts show major differences in speciation. The formation of selenomethionine selenoxide and the identification of Se-S bonded $S$-(selenomethyl)-cysteine in archived nutritional yeast may be important for short and long term stability and nutritional activity studies.

\section{Introduction}

Selenium has a vital nutritional role and has cancer chemopreventive properties, but the speciation of selenium compounds, which is needed to define their biological roles, presents a great challenge. ${ }^{1}$ The study of selenium toxicity above the limited range of nutritional necessity also mandates high accuracy and precision in selenium speciation. Ionic selenium and organoselenium compounds, selenoamino acids and related compounds, are present in a diverse range in both enriched and natural matrixes. The human nutritional metabolic need for selenium derives from its incorporation into the active selenol group $(-\mathrm{SeH})$ centers of glutathione peroxidase, thioredoxin reductase and other selenoenzymes. ${ }^{2,3}$ Cancer chemoprevention is associated with inorganic selenium salts, selenoamino acids and organoselenium compounds such as methaneselenol $\mathrm{CH}_{3} \mathrm{SeH}^{4}{ }^{4-6}$ Selenoproteins contain selenium in the form of selenocysteinyl residues; proteins that contain this element in the form of selenomethionyl residues are not formally classified as selenoproteins. Analytical techniques for the determination of selenium species have been reviewed, ${ }^{7-10}$ but many methods have only been applied to a few commercially available standards. Table 1 shows some selenium species that have attracted nutritional, clinical and bioanalytical attention.
Treatment of selenium-containing samples with proteolytic enzymes, followed by extraction, enables more than $90 \%$ of total selenium to be recovered and speciated, perfluoro acid ion pair reversed phase HPLC giving good separation of selenite, selenate, methaneseleninic acid, selenoamino acids, selenoxides, etc. HPLC interfaced with the inductively coupled plasma mass spectrometer (ICP-MS) gives total element determination and selenium specific detection to low ppb levels and has been applied to a number of natural and enhanced level selenium speciation studies. ${ }^{4,11-17}$ Volatile compounds such as dialkyl selenides and selenoamino acid derivatives have been determined by headspace-capillary gas chromatography with atomic emission element specific detection (GC-AED). ${ }^{17,18}$

Selenium-enriched yeast supplements have given statistically significant reductions in cancer incidence and mortality in human intervention trials ${ }^{19}$ and it has been shown that highselenium garlic is effective in rat mammary cancer chemoprevention. ${ }^{20}$ It has been proposed that anti-tumorigenic activity arises from selenomethionine (SeMet) and selenocysteine (SeCys), and methylated forms such as $S e$-methyl-SeCys that are converted to metabolites, including methaneselenol $\left(\mathrm{CH}_{3} \mathrm{SeH}\right){ }^{5,21}$ 'High Selenium Yeast' was developed to meet the need for a reliable, biologically available source of selenium. Under agreements with the Division of Cancer

Table 1 Inorganic and organoselenium analytical target compounds

\begin{tabular}{|c|c|c|c|c|c|}
\hline 1 & Selenous acid, selenite & $\mathrm{SeO}_{3}{ }^{2-}$ & 2 & Selenic acid, selenate & $\mathrm{SeO}_{4}{ }^{2-}$ \\
\hline 3 & Selenocyanate & $\mathrm{SeCN}^{-}$ & 4 & Methaneseleninic acid anion & $\operatorname{MeSe}(\mathrm{O}) \mathrm{O}^{-}$ \\
\hline 5 & Methaneselenenic acid anion & $\mathrm{MeSeO}^{-}$ & 6 & Dimethyl selenide & $\mathrm{Me}_{2} \mathrm{Se}$ \\
\hline 7 & Dimethyl diselenide & $\mathrm{Me}_{2} \mathrm{Se}_{2}$ & 8 & Methaneselenol & $\mathrm{MeSeH}$ \\
\hline 9 & Trimethylselenonium cation & $\mathrm{Me}_{3} \mathrm{Se}^{+}$ & & & \\
\hline 10 & Selenocysteine & \multicolumn{4}{|c|}{$\mathrm{H}_{3} \mathrm{~N}^{+}-\mathrm{CH}\left(\mathrm{COO}^{-}\right)-\mathrm{CH}_{2}-\mathrm{SeH}$} \\
\hline 11 & Selenocystine & \multicolumn{4}{|c|}{$\mathrm{H}_{3} \mathrm{~N}^{+}-\mathrm{CH}\left(\mathrm{COO}^{-}\right)-\mathrm{CH}_{2}-\mathrm{Se}-\mathrm{Se}-\mathrm{CH}_{2}-\mathrm{CH}\left(\mathrm{COO}^{-}\right)-\mathrm{NH}_{3}{ }^{+}$} \\
\hline 12 & Selenomethionine & \multicolumn{4}{|c|}{$\mathrm{H}_{3} \mathrm{~N}^{+}-\mathrm{CH}\left(\mathrm{COO}^{-}\right)-\mathrm{CH}_{2}-\mathrm{CH}_{2}-\mathrm{Se}-\mathrm{Me}$} \\
\hline 13 & Selenomethionine oxide hydrate & \multicolumn{4}{|c|}{$\mathrm{H}_{3} \mathrm{~N}^{+}-\mathrm{CH}\left(\mathrm{COO}^{-}\right)-\mathrm{CH}_{2}-\mathrm{CH}_{2}-\mathrm{Se}(\mathrm{OH})_{2}-\mathrm{Me}$} \\
\hline 14 & Se-Methylselenocysteine & \multicolumn{4}{|c|}{$\mathrm{H}_{3} \mathrm{~N}^{+}-\mathrm{CH}\left(\mathrm{COO}^{-}\right)-\mathrm{CH}_{2}-\mathrm{Se}-\mathrm{Me}$} \\
\hline 15 & $\gamma$-Glutamyl-methylselenocysteine & \multicolumn{4}{|c|}{$\mathrm{H}_{3} \mathrm{~N}^{+}-\mathrm{CH}_{2}-\mathrm{CH}_{2}-\mathrm{CO}-\mathrm{NH}-\mathrm{CH}\left(\mathrm{COO}^{-}\right)-\mathrm{CH}_{2}-\mathrm{Se}-\mathrm{Me}$} \\
\hline 16 & Selenocystathionine & \multicolumn{4}{|c|}{$\mathrm{H}_{3} \mathrm{~N}^{+}-\mathrm{CH}\left(\mathrm{COO}^{-}\right)-\mathrm{CH}_{2}-\mathrm{CH}_{2}-\mathrm{Se}-\mathrm{CH}_{2}-\mathrm{CH}\left(\mathrm{COO}^{-}\right)-\mathrm{NH}_{3}^{+}$} \\
\hline 17 & Selenohomocysteine & \multicolumn{4}{|c|}{$\mathrm{H}_{3} \mathrm{~N}^{+}-\mathrm{CH}\left(\mathrm{COO}^{-}\right)-\mathrm{CH}_{2}^{-}-\mathrm{CH}_{2}^{-}-\mathrm{SeH}$} \\
\hline 18 & Se-Adenosylselenohomocysteine & \multicolumn{4}{|c|}{$\mathrm{NH}_{2}-\mathrm{CH}(\mathrm{COOH}) \mathrm{CH}_{2} \mathrm{CH}_{2} \mathrm{SeCH}_{2} \mathrm{C}_{4} \mathrm{H}_{5} \mathrm{O}_{3} \mathrm{C}_{5} \mathrm{~N}_{4} \mathrm{NH}_{2}$} \\
\hline
\end{tabular}


Prevention, National Cancer Institute (DCP-NCI), clinical trials have been initiated to test hypotheses that Se-supplementation improves health by reducing risks of cancers of the colon, lung and prostate. The Clark study ${ }^{19}$ is now being extended in the 'SELECT'-Selenium and Vitamin E Cancer Prevention Trial, which will monitor the incidence of prostate cancer in 32400 healthy men over a 12-year study period, in which selenomethionine will be employed as the selenium dosage agent. ${ }^{22}$ The DCP-NCI has noted that, should these studies confirm the previously reported cancer-protective effects of Se, then two further steps will be required in order to ascribe clinical benefit to the dietary supplement. The Secompounds in the supplement must be identified and evidence of batch-to-batch reproducibility with respect to those Secompounds must be available. Analyses of commercially available preparations have shown organically-bound Se to vary in range from 0 to $97 \%$ of total Se content, with some products showing only a few Se-species and others containing more than 20 different Se-compounds. ${ }^{11,16,23,24}$

A typical commercially available selenized yeast such as SelenoExcell ${ }^{\circledR}$ (Cypress) has a Se content of $1250 \mu \mathrm{g} \mathrm{g}^{-1}$ dry matter $( \pm 5 \%)$, a minimum protein content of $50 \%(\mathrm{w} / \mathrm{w})$, and a phosphate content in the range of $2.5-3.4 \%$ (w/w). However, because it is a biological product, batch-to-batch variation in its composition is possible, requiring informative and rigorous QA/QC protocols. The greater part of the Se in SelenoExcell ${ }^{\circledR}$ is organically bound, and the major single component (released from the protein-bound form by enzymatic digestion and extraction) is selenomethionine (SeMet), comprising $60-70 \%$ of the total Se. ${ }^{11}$ However, it is possible that selenized yeast may contain organoselenium species or precursors that may be more anti-carcinogenically potent than SeMet.

We now report a more extensive characterization study of a number of yeast samples, including elucidation of changes in Se speciation upon lengthy storage and, in particular, speciation of material used in the human intervention trial of Clark et al. ${ }^{19}$ The complementary techniques of HPLC-ICP-MS and GCAED were used to characterize the materials.

\section{Experimental}

\section{Instrumentation}

An Elan 5000 inductively coupled plasma mass spectrometer (PerkinElmer Sciex, Norwalk, CT, USA) was used for total selenium determination and HPLC-ICP-MS. Samples were introduced using a cross-flow nebulizer and double-pass spray chamber. For total selenium determination ${ }^{82} \mathrm{Se}$ and ${ }^{77} \mathrm{Se}$ were monitored with ${ }^{74} \mathrm{Ge}$ as an internal standard using a $250 \mathrm{~ms}$ dwell time $(n=27)$; isobaric interference from ${ }^{74} \mathrm{Se}$ was automatically corrected as confirmed for certified materials. ${ }^{16}$ The chromatographic system consisted of a liquid chromatographic pump (SP8810, Spectra-Physics, San Jose, CA, USA), and either a $5 \mu \mathrm{m}$ Symmetry Shield RP8 bonded hybrid stationary phase column $(3.9 \mathrm{~mm} \times 15 \mathrm{~cm})$ or a $5 \mu \mathrm{m}$ XTerra $\mathrm{RP}_{-} \mathrm{C}_{18}$ column $((4.6 \mathrm{~mm} \times 15 \mathrm{~cm})$ Waters Corporation, Milford, MA, USA), that has a polar modifier group between the $\mathrm{C}_{8}$ group and the silica base. The column was connected to the nebulizer with PEEK tubing $(30 \mathrm{~cm} \times 0.25 \mathrm{~mm}$ id). The mobile phase compositions were as follows: $99+1$ (v/v) watermethanol was used in each case with (a) $0.1 \%$ trifluoroacetic acid (TFA) or (b) $0.1 \%$ heptafluorobutanoic acid (HFBA).

A Hewlett-Packard HP 5921A atomic emission detector (AED) interfaced with a HP 5890II gas chromatograph was used. The injection port (splitless) was maintained at $250{ }^{\circ} \mathrm{C}$ : the GC oven was programmed from $100^{\circ} \mathrm{C}$ (initial temperature for $5 \mathrm{~min}$ ) to $200^{\circ} \mathrm{C}$ at $5{ }^{\circ} \mathrm{C} \mathrm{min}^{-1}$, holding at $200^{\circ} \mathrm{C}$ for $5 \mathrm{~min}$. A HP $125 \mathrm{~m} \times 0.32 \mathrm{~mm} \times 0.17 \mu \mathrm{m}$ (film thickness) column was used. The helium plasma gas flow was kept at $180 \mathrm{ml}$ $\min ^{-1}$. Hydrogen was used as reagent gas, with detection at $181 \mathrm{~nm}(\mathrm{~S})$ and $196 \mathrm{~nm}(\mathrm{Se})$.

A HP mass selective detector (Hewlett-Packard Co.) interfaced with a HP 6890 GC was used for GC-MS analysis, using a HP-5 (5\% phenyl, 95\% polydimethylsiloxane, $30 \mathrm{~m} \times$ $0.25 \mathrm{~mm} \times 0.25 \mu \mathrm{m})$ column. The oven was run at an isothermal temperature of $160{ }^{\circ} \mathrm{C}$ and helium was used as a

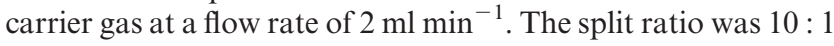
and the column head pressure was 13.28 psi.

\section{Chemicals}

Sodium selenate, sodium selenite, DL-selenomethionine, DLselenoethionine, DL-selenocystine, Protease XIV, and ethyl chloroformate (ECF) were obtained from Sigma Chemical Company (St. Louis, MO, USA). Se-Methyl-DL-selenocysteine was obtained from Dr. Howard Ganther (University of Wisconsin, Madison, WI, USA). Plasma selenium and germanium standard solutions $\left(1000 \mu \mathrm{g} \mathrm{ml}^{-1}\right)$ were obtained from Spex Industries Inc., Edison, NJ, USA. Seleniumenriched yeast (SelenoExcell ${ }^{(i}$, also designated SelenoPrecise) was obtained from Cypress Inc., Fresno, CA, USA. Archived selenized yeast and tablets fabricated from it, as employed in the human intervention trials, ${ }^{19}$ were obtained from the University of Arizona, McKesson Corp. and Cornell University (archive numbered as N1-N13). Stock solutions of selenoamino acids were prepared in $0.2 \mathrm{M} \mathrm{HCl}$. A stock solution of sodium selenate was prepared in $2 \%(\mathrm{v} / \mathrm{v}) \mathrm{HNO}_{3}$, while the plasma selenium standard was used as a stock solution of sodium selenite. Working solutions were diluted with mobile phase and stored in the dark between $0-4{ }^{\circ} \mathrm{C}$. The standards used in measurements were thus $0.02-0.002 \mathrm{M}$ in $\mathrm{HCl}$ or $0.0002 \%$ in $\mathrm{HNO}_{3}$ after dilution, these acid concentrations having no effect on chromatographic separation and speciation considering the $10 \mu \mathrm{L}$ volumes injected.

\section{Procedure}

Sample preparation for HPLC. The enzymatic digestion/ extractions followed the procedures reported earlier and are only briefly summarized. ${ }^{11}$ Five $\mathrm{ml}$ of distilled deionized water was added to $0.2 \mathrm{~g}$ of powdered sample together with $0.02 \mathrm{~g}$ of 'Protease XIV' enzyme in a $15 \mathrm{~mL}$ centrifuge tube, then the mixture was shaken for $24 \mathrm{~h}$ at room temperature. After the digestion and extraction, the samples were centrifuged at $3000 \mathrm{~g}$ for $20 \mathrm{~min}$ and filtered successively through a $0.45 \mu \mathrm{m}$ polypropylene filter and an 'Ultrafree' centrifugal filter (Millipore Corp., Bedford, MA) having a 10000 Dalton molecular weight cut-off. Samples were acidified before injection $(900 \mu \mathrm{l}$ of extract plus $100 \mu \mathrm{l}$ of concentrated HFBA, i.e. $10 \%$ HFBA in extract).

Derivatization of standard selenoamino acids for GC-AED and GC-MS. Selenoamino acid standards were derivatized with ethylchloroformate (ECF) using the method developed by Husek. ${ }^{25}$ Stock solutions of the amino acids were prepared by weighing $10 \mathrm{mg}$ of the standard and dissolving in $1 \mathrm{ml}$ of $0.1 \mathrm{M}$ $\mathrm{HCl}$ to make $10000 \mathrm{ppm}$ standard solutions. Then, $1000 \mathrm{ppm}$ derivatized standard solutions were prepared as follows: $100 \mu \mathrm{l}$ of the $10000 \mathrm{ppm}$ selenoamino acid stock solution was treated with $1 \mathrm{ml}$ of water-ethanol-pyridine mixture (60:32:8), $50 \mu \mathrm{l}$ of ECF was added and the mixture shaken until gas evolution ceased. Then, $1 \mathrm{ml}$ of chloroform (containing $1 \%$ ECF) was added and the derivatives were extracted into the organic phase which was evaporated to dryness. The residue was redissolved in $1 \mathrm{ml}$ of hexane and $1 \mu \mathrm{l}$ was injected into the GC-AED or GC-MS.

A 2-ml portion of the aqueous (non-acidified) extract prepared for HPLC analysis was also taken for examination by GC-AED. A water-ethanol-pyridine mixture $(60: 32: 8$ by 
volume $-15 \mathrm{ml}$ ) was added followed by ethyl chloroformate $(\mathrm{ECF}-1 \mathrm{ml})$, the sample was shaken and any evolved gas vented. Ethylated derivatives were extracted into $3 \mathrm{ml}$ of chloroform (containing 1\% ECF) by shaking for $30 \mathrm{~min}$. The chloroform layer was separated, solvent was removed with a flow of nitrogen and the residue was redissolved in $100 \mu \mathrm{l}$ chloroform or hexane. One $\mu$ l was injected.

Liquid chromatographic methods. The separation, qualitative identification and quantitative determination of the wide range of inorganic selenium and organoselenium present or potentially present in the complex samples requires the application of a complementary range of state-of-the art techniques.

High-performance liquid chromatography provides the core methodology, since some of the target chemical species are not directly amenable to gas phase separations. However, the need is to develop and apply a complementary suite of separation methods which, when applied together, will give the greatest confidence of reliable information.

While ion exchange chromatography has been extensively applied, we have found reversed phase ion pair HPLC to be successful. Incorporation of a fluorinated acid ion-pairing agent to establish a pH of $c a$. 2-2.5 enables anions such as selenite, selenate, etc., to be protonated completely to give neutral species that are eluted rapidly. Cationic (positive) species, such as trimethylselenonium, are paired with the fluorinated acid anion to give 'neutral' ion pairs and are retained somewhat more. Selenoamino acids are protonated and also 'ion paired' with the fluoroacid anions and elute at different times depending upon their degree of retention on the stationary phase. Different fluorinated acids provide different degrees of separation in different regions of the chromatogram. Larger molecules, such as peptides and proteins, are not eluted and separated by this procedure, although intermediate species such as $S e$-adenosyl-selenohomocysteine and $\gamma$-glutamyl- $S e$ methylselenocysteine can be eluted in a reasonable time frame.

\section{Results and discussion}

Selenium specific HPLC-ICP-MS chromatograms of enzymatic (Protease XIV) hydrolyzate products from a $1250 \mathrm{ppm}$ reference yeast (SelenoExcell ${ }^{(i)}$ ), obtained on the Symmetry Shield ${ }^{\circledR}$ column, are shown in Fig. 1. The response scale of the lower chromatogram is expanded approximately 25 -fold. In this case selenomethionine is clearly the major selenium species eluted. In terms of percentage selenium distributions, as expressed as total selenium area response of eluted peaks (a valid approach since selenium response is independent of molecular structures), selenomethionine comprised $84 \%$ of eluted selenium. The only other positively identified selenium compounds were selenite $(0.1 \%), \gamma$-glutamyl-Se-methyl-selenocysteine $(0.5 \%)$ and Se-adenosylselenohomocysteine $(0.5 \%)$, as authenticated by retention of standards and HPLC-MS. We have reported a similar separation for a more highly enriched yeast (1922 ppm Se-Nutrition 21, San Diego, CA). ${ }^{11}$ For the latter yeast there were indications of other selenium compounds including Se-cystathionine, Se-lanthionine and Semethylselenocysteine at levels too low for mass spectral confirmation. In these chromatograms an 'unknown' selenium peak that does not correspond to any known standards but comprises $c a .5 \%$ of eluted selenium, elutes at $c a .2 .5 \mathrm{~min}$ on the Symmetry Shield ${ }^{\circledR}$ column (U1). Another small unidentified peak (ca. 2\%-eluted selenium) appears at $c a .10 .5 \mathrm{~min}$ (U2). U1 proves to be related to the oxidation of selenomethionine, as is shown subsequently. We show $\mathrm{U} 2$ to be a previously unidentified organoselenium species.

Replicate determinations made for multiple samples of SelenoExcell ${ }^{\circledR}$ ( $n=3$ for each of 3 batches) produced
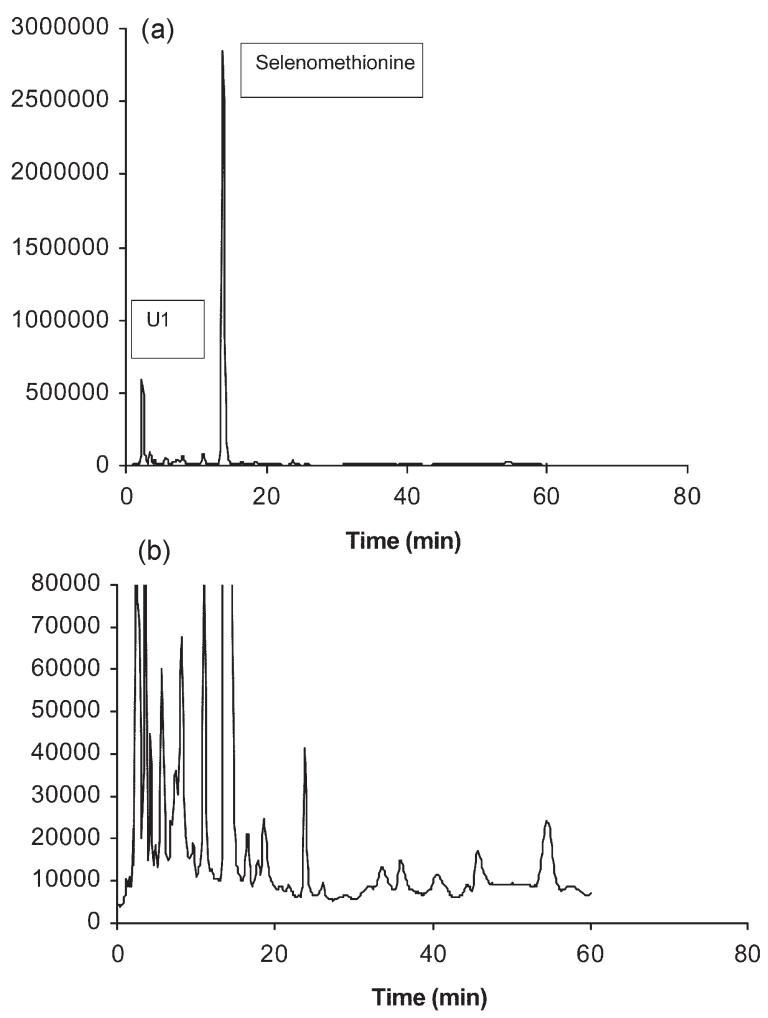

Fig. 1 Se-specific HPLC-ICP-MS chromatograms of the enzymatic hydrolysis of $1250 \mathrm{ppm}$ Se yeast (reference) using $0.1 \%$ HFBA ion pairing agent, Symmetry Shield ${ }^{\left({ }^{\infty}\right.}$ column (lower-Se-82 counts $\mathrm{s}^{-1}$ response scale expanded).

chromatograms (as in Fig. 1) which could be overlaid and showed RSD values for the quantitation of identified components of $1 \%$ or better. Provided that the Protease XIV enzyme employed for digestion was kept at $-40{ }^{\circ} \mathrm{C}$ when not in use, virtually no changes in chromatographic profiles were seen in six months. This 'reference' yeast reproducably showed $c a$. $13-14 \%$ of total chromatographable selenium eluted before selenomethionine and less than $1 \%$ eluted after that peak. Each time a new group of experiments were run or a new sample of Protease XIV was used the 'reference' yeast was determined to confirm consistent analytical behavior.

Table 2 shows the percentage compositions of the four previously identified selenium species obtained for a number of selenized yeasts with different total selenium contents. Total eluted selenium referenced against element content range from $69.2-94 \%$, repeatability values being as noted above. Of this elutable selenium, the selenomethionine percentage ranged from $62.5 \%$ to $89.1 \%$, selenite was always very low, but the $\mathrm{Se}$-adenosylselenohomocysteine content varied more widely (0.5-7.4\%). Unknown peaks U1 and, to a lesser extent, U2 were also present in the low percent range.

\section{Selenium-enriched nutritional tablets ${ }^{19}$}

Previously reported selenium speciation and quantitation showed markedly different results for selenium-enriched tablets obtained from various sources. Sutton et al. in particular ${ }^{23}$ noted a wide variation among supplement tablets. A typical supplement tablet weighs $c a .500 \mathrm{mg}$ and contains $200 \mu \mathrm{g}$ of selenium present in $160 \mathrm{mg}$ of selenized yeast. The remaining excipients comprise a range of ingredients such as calcium phosphate, cellulose gel, stearic acid, silica, hydroxypropylcellulose, magnesium stearate and polyethylene glycol, but no specific antoxidants.

As part of an on-going study related to the National Cancer Institute human intervention trials previously reported ${ }^{19}$ and proposed for the future, ${ }^{22}$ samples of selenium-enriched tablets 
Table 2 Selenium compounds determined in enzymatic extracts of yeast samples with different total selenium content

\begin{tabular}{|c|c|c|c|c|c|c|c|c|c|}
\hline $\begin{array}{l}\text { Se-species } \\
\text { (Table 1) }\end{array}$ & $\begin{array}{l}1250 \mathrm{ppm} \\
\text { yeast }\end{array}$ & $\begin{array}{l}1204 \mathrm{ppm} \\
\text { yeast }\end{array}$ & $\begin{array}{l}1258 \mathrm{ppm} \\
\text { yeast }\end{array}$ & $\begin{array}{l}1406 \mathrm{ppm} \\
\text { yeast }\end{array}$ & $\begin{array}{l}1500 \mathrm{ppm} \\
\text { yeast }\end{array}$ & $\begin{array}{l}550 \mathrm{ppm} \\
\text { yeast }\end{array}$ & $\begin{array}{l}1200 \mathrm{ppm} \\
\text { yeast }\end{array}$ & $\begin{array}{l}1220 \mathrm{ppm} \\
\text { yeast }\end{array}$ & $\begin{array}{l}1150 \mathrm{ppm} \\
\text { yeast }\end{array}$ \\
\hline 1 & $0.09 \%$ & $0.2 \%$ & $0.4 \%$ & $0.4 \%$ & $0.04 \%$ & $0.03 \%$ & $0.1 \%$ & $0.09 \$$ & $0.5 \%$ \\
\hline 12 & $84 \%^{a}$ & $77.2 \%$ & $62.5 \%$ & $77.4 \%$ & $83.3 \%$ & $89.1 \%$ & $66.5 \%$ & $74.5 \%$ & $74 \% \%^{a}$ \\
\hline 15 & $0.54 \%$ & $0.9 \%$ & $1.6 \%$ & $1.2 \%$ & $0.9 \%$ & $0.1 \%$ & $0.9 \%$ & $0.9 \%$ & - \\
\hline 18 & $0.5 \%^{a}$ & $0.9 \%$ & $4.7 \%$ & $7.4 \%$ & $5 \%$ & $4.8 \%$ & $5.9 \%$ & $4.4 \%$ & - \\
\hline SUM & $85.1 \%$ & $79.2 \%$ & $69.2 \%$ & $86.3 \%$ & $89.2 \%$ & $94 \%$ & $73.4 \%$ & $79.9 \%$ & $74.5 \%$ \\
\hline
\end{tabular}

$a \% \mathrm{Se}$ distributions are expressed in terms of total selenium content eluting from the column. Compounds with distribution percentage values marked with an asterisk were confirmed by HPLC-ESI-MS.

used in the former trial were obtained from archived samples. Representative tablets were crushed, after first manually removing titanium dioxide coatings if present, and treated enzymatically according to the standard protocol. Tablets were chosen from various time periods of the trial from 1986-1993
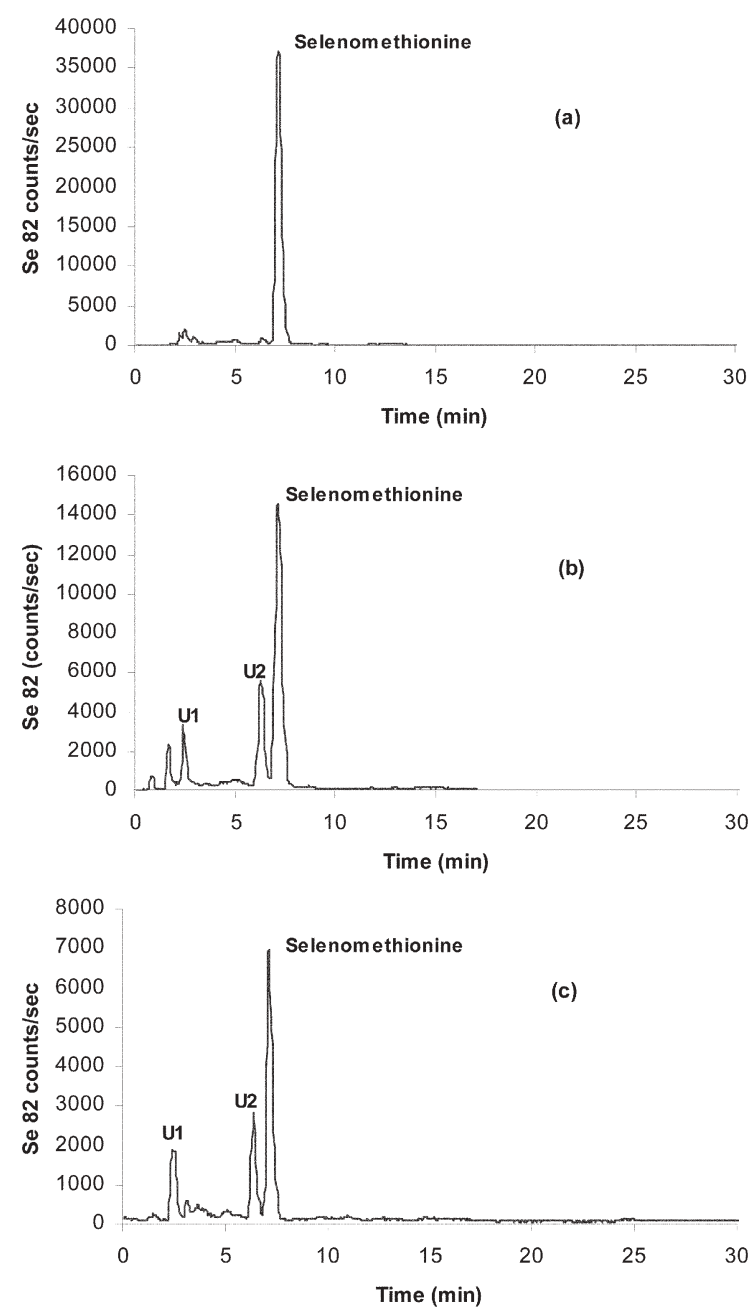

Fig. 2 HPLC-ICP-MS chromatograms of the enzymatic hydrolysis of (a) SelenoExcell ${ }^{(0)}$ yeast, (b) Clark yeast and (c) Clark yeast tablet (N5), using $0.1 \%$ HFBA as ion-pairing agent. XTerra ${ }^{(m)}$ column and are designated N2, N5, N8 and N13. A more comprehensive survey of the results from this study will be published elsewhere. A representative HPLC-ICP-MS chromatogram is shown in Fig. 2 for sample N5, showing a striking difference from the selenized yeasts analyzed previously. While selenomethionine is still present, it occurs in a much lower proportion and 'unknowns' U1 and U2 now appear as the predominant components. In all archived tablets examined these three peaks predominate in various proportions. Table 3 shows representative quantifiation of four archived tablets. Each result is for replicate analyses for representative samples from 10 pooled tablets of each batch. Repeatability was as noted above for yeast samples.

Since all of the archived tablets showed substantially different selenium profiles from the reference selenized yeast, it appears that changes in speciation (as determined following enzymatic treatment and extraction) have occurred, either from lengthy storage, perhaps by oxidation, by interaction with tablet excipients or perhaps by linked processes. An important observation suggests that excipients in tablets are not involved since a selenized yeast powder obtained from the University of Arizona archives designated as 'Clark yeast', which was used in the preparation of ' $N$ ' series samples, gave a profile very similar to that of N5 (Fig. 2). Fig. 2 also compares these profiles with that of reference yeast powder employed to prepare currently manufactured selenized yeast tablets (SelenoExcell ${ }^{\circledR i}$ ).

\section{Oxidation of selenoamino acids}

The selenoxides of selenoamino acids have been found in natural samples ${ }^{26-29}$ and, in the case of selenized yeasts or nutritional supplement extracts, selenium compounds eluting early under reversed phase mobile phase conditions, may be such oxidation products.

Amino acid selenoxides have been synthetically produced and studied, primarily because of interest in the antioxidant activity of selenium. Gammelgaard et al. recently carried out an exhaustive study of the oxidative degradation of selenomethionine. ${ }^{30}$ These workers separated oxidation products during the course of the process and used ICP-MS, LC-MS and NMR to identify major compounds. Selenomethionine selenoxide and methaneseleninic acid were fully characterized.

We have previously reported the examination of oxidation of selenoamino acids by HPLC-ICP-MS and found differing products for different acids. ${ }^{11,12}$ In particular, small $\mathrm{pH}$ changes in HPLC separation conditions may give rise to

Table 3 Selenium distribution (\%) in the archived selenized yeast tablet extracts

\begin{tabular}{|c|c|c|c|c|c|c|c|c|}
\hline & 1 & 2 & 12 & 15 & 18 & U-1 & $\mathrm{U}-2$ & Sum \\
\hline N2 & - & 9.5 & 8.4 & - & - & 58.3 & 17.3 & 93.5 \\
\hline N5 & - & 2.9 & 24.6 & 1.3 & 3.1 & 52.8 & 10.9 & 95.6 \\
\hline N8 & - & 3.3 & 19.5 & - & 2.4 & 38.9 & 21.6 & 85.7 \\
\hline N13 & - & 11 & 7.4 & - & 2.2 & 54.3 & 15.5 & 90.4 \\
\hline
\end{tabular}


data needing careful interpretation, especially as regards retention time shifts. Thus, while the primary product of peroxide oxidation of selenomethionine is selenomethionine selenoxide hydrate, oxidation of $\mathrm{Se}$-methylselenocysteine generates methaneseleninic acid among other products. ${ }^{11,26}$ The treatment of SelenoExcell ${ }^{\circledR}$ yeast with excess hydrogen peroxide was now investigated, and the major product identified as selenomethionine selenoxide hydrate elutes at $c a .2 .5 \mathrm{~min}$ on the Symmetry Shield ${ }^{(i}$ column. In addition, a small amount of selenite is present after the oxidation.

In the enzymatic extraction of SelenoExcell ${ }^{\circledR}$ yeast two major components were found: selenomethionine and "U1" at ca. 2.5 min on the Symmetry Shield ${ }^{(m)}$ column (Fig. 1). Since "U1" elutes in the early part of the chromatogram it is considered to be hydrated selenomethionine selenoxide. This is minimally retained due to the enhanced polarity imparted by the addition of oxygen and the elements of water to the selenium atom, producing greater affinity for the acidic aqueous mobile phase. The formation of the hydrate under such acid conditions has been reported elsewhere. ${ }^{30,31}$ The mass spectrum of oxidized selenomethionine was confirmed as reported by Bird to indicate the presence of hydrated selenomethionine selenoxide with a selenium ion cluster (Se80 molecular ion at $\mathrm{m} / \mathrm{z} 232) .{ }^{32}$ Larsen et al. have described an ion exchange HPLC-ICP-MS study in which selenomethionine selenoxide was observed and confirmed. ' ${ }^{14} 2$ ' is chromatographically retained similarly to selenomethionine and thus is considered to have a considerably less polar structure than the hydrate. Its retention is in the region typically seen for ion paired selenamino acids.

\section{Reduction of oxidized SelenoExcell ${ }^{(i x}$}

As was noted earlier, ${ }^{16}$ the oxidation of selenomethionine to selenomethionine selenoxide is reversible upon reduction by thiosulfate in aqueous solution, as shown by proton NMR. ${ }^{33}$ For selenomethionine standards, we confirmed earlier by HPLC-ICP-MS that quantitative recovery of non-oxidised selenomethionine occurs upon treating the hydrated selenomethionine selenoxide with excess thiosulfate. ${ }^{16}$

Upon addition of thiosulfate to oxidized SelenoExcell ${ }^{(m)}$ yeast extract, the peak considered to be selenomethionine selenoxide hydrate reverted to selenomethionine, the chromatographic profile of which was, however, complicated by broadening and double peaking, the extent of which was dependent on the amount of thiosulfate added with resulting $\mathrm{pH}$ change. Such behavior was attributed to equilibrium between non-protonated and protonated/ion paired forms of selenomethionine. ${ }^{13}$ Coincidentally this chromatographic peak behavior overlapped with U2 and led initially to an erroneous conjecture that U2 corresponded to another 'derivative' of selenomethionine, perhaps the nonhydrated selenomethionine selenoxide. This supposition was, however, considered unlikely since at the $\mathrm{pH}$ of the HFBA mobile phase of 2.55 , only the hydrated form would be expected. ${ }^{13}$ This behavior prevented the archived samples from being usefully subjected to the oxidation-reduction sequence as $\mathrm{U} 2$ was masked by the behavior of selenomethionine. The need for an alternative independent analytical procedure to elucidate U2 was clear.

\section{Gas chromatography}

Capillary gas chromatography provides sensitive, high-resolution analysis for analytes of sufficient volatility, or following chemical derivatization to convert non-volatile species to volatile ones. When coupled with atomic emission detection (AED), selenium in target molecules is directly monitored by spectroscopic detection of atomic emission radiation at a wavelength characteristic of the element, providing both qualitative elemental speciation and quantitation. ${ }^{34,35} \mathrm{We}$

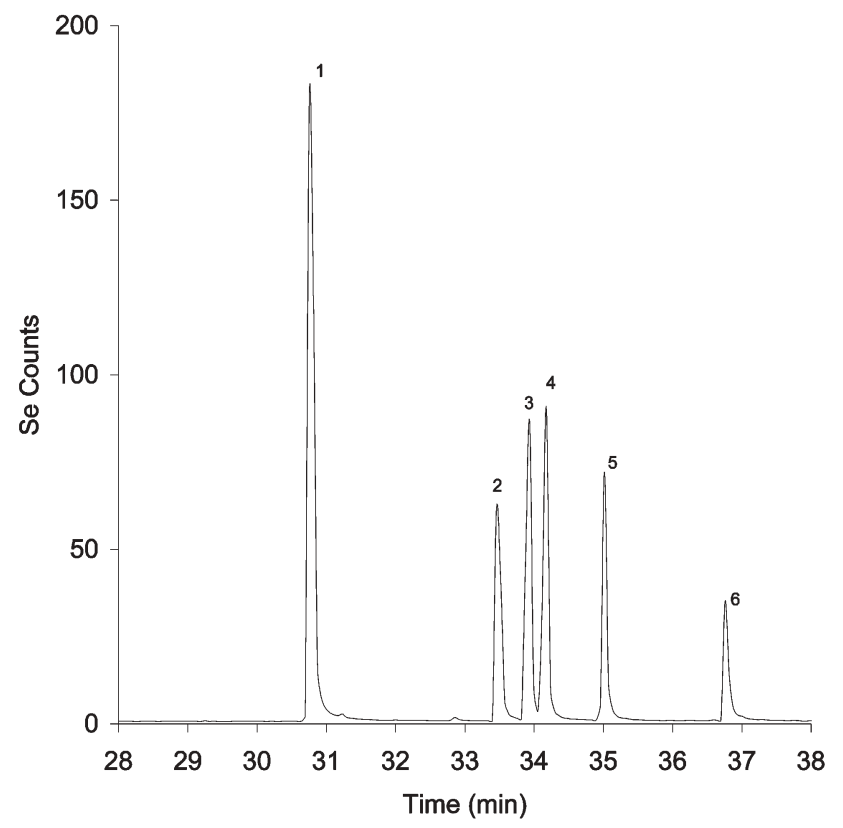

Fig. 3 GC-AED temperature programmed chromatogram of derivatized selenoaminoacids. (1) Se-methylselenocysteine, (2) selenomethionine, (3) Se-allylselenocysteine, (4) Se-propylselenocysteine, (5) selenoethionine and (6) selenocysteine.

have used GC-AED to detect and determine many volatile organoselenium compounds present in or produced by plants such as garlic, elephant garlic, onion and broccoli. ${ }^{21} \mathrm{~A}$ common structure is $\mathrm{R}-\mathrm{S}_{x}\left(\mathrm{Se}_{y}\right)-\mathrm{R}^{\prime}$, where $\mathrm{R}$ and $\mathrm{R}^{\prime}$ are methyl or allyl groups.

Derivatization with alkyl chloroformates provides an effective route to volatile species for amino acid GC. Selenoamino acids have been derivatized for $\mathrm{GC}$ with isopropyl chloroformate, ${ }^{36}$ and ethyl chloroformate; selenocysteine, Se-methylselenocysteine and selenomethionine have been determined in normal and selenium-enriched plants using GC-AED. ${ }^{37,38}$

Depicted in Fig. 3 is a GC-AED chromatogram (Se at $196 \mathrm{~nm}$ ) of the ethyl chloroformate derivatives of six selenoamino acids, all of which elute within a seven minute window with excellent resolution and peak efficiencies. The retention times of these species are shown in Table 4. The longer retention time of the selenocysteine derivative results from the fact that derivatization takes place at the $\mathrm{Se}-\mathrm{H}$ group as well as the amino and carboxylate functions.

Fig. 4 shows the GC-AED (Se at $196 \mathrm{~nm}$ ) of derivatized Clark yeast and SelenoExcell ${ }^{(i \pi}$ yeast extract prepared by the Protease XIV digestion of yeast powders, and of derivatized selenomethionine as a reference. These were the same samples as investigated by HPLC-ICP-MS as described earlier. It is apparent (Fig. 4) that the Clark yeast chromatogram contains more peaks than the SelenoExcell ${ }^{(i m}$ or selenomethionine chromatograms. Particularly interesting is the peak appearing at $c a .35 \mathrm{~min}$ in the region corresponding to derivatized selenoamino acids. In Fig. 5 a comparison of selenium chromatograms for archived N2, N5 and N8 archived tablets prepared

Table 4 Standard derivatized selenium compounds in a standard solution with their molecular weights (for Se 80) and retention times

\begin{tabular}{lll}
\hline Name & $\begin{array}{l}\text { Molecular } \\
\text { weight }\end{array}$ & $\begin{array}{l}\text { Retention } \\
\text { time/min }\end{array}$ \\
\hline Se-Methylselenocysteine derivative & 283 & 30.75 \\
Selenomethionine derivative & 297 & 33.52 \\
Se-Allylselenocysteine derivative & 309 & 33.95 \\
Se-Propylselenocysteine derivative & 311 & 34.20 \\
Selenoethionine derivative & 311 & 35.00 \\
Selenocysteine derivative & 341 & 36.75
\end{tabular}




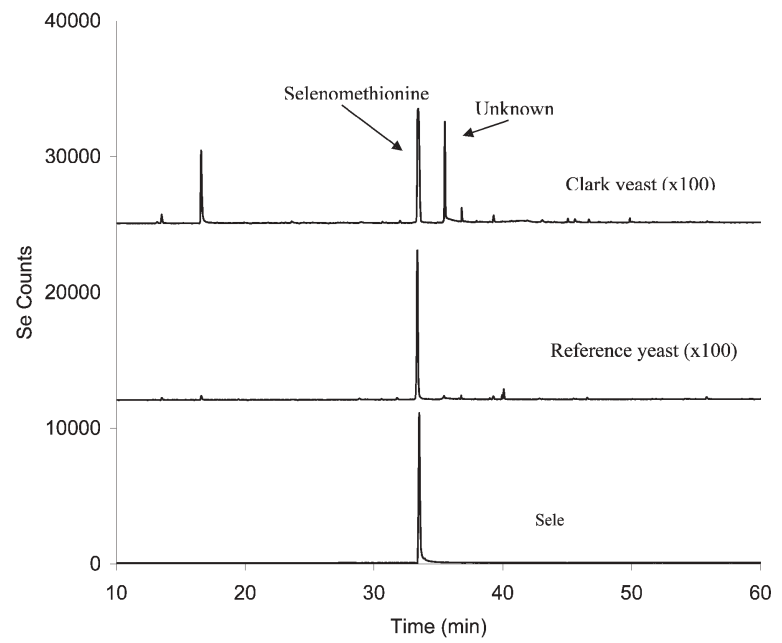

Fig. 4 GC-AED (Se 196 nm) of derivatized selenomethionine, Clark yeast and SelenoExcell ${ }^{(i x}$ yeast. Baseline offset for display purposes: Reference yeast trace, baseline is at +12000 counts; Clark yeast trace, baseline is at +25000 counts.

by Protease XIV digestion followed by derivatization are seen. The selenium-containing component at $35 \mathrm{~min}$ appears for each of the tablets to varying degrees.

A key advantage of GC-AED is the facility to display simultaneously a number of element specific chromatograms for different elements. In this fashion, carbon, sulfur and selenium chromatograms can be displayed simultaneously. Fig. 6 shows comparative C, S and Se chromatograms for the Clark yeast. The selenium and sulfur traces indicate the presence of both of these elements in the peak eluting at $c a$. 35 min. Independent calibrations performed to estimate relative responses of $\mathrm{S}$ and $\mathrm{Se}$ under the set plasma conditions, using derivatized methionine and selenomethionine as standards, ${ }^{39}$ showed the selenium response at $196 \mathrm{~nm}$ to be approximately four times the sulfur response at $181 \mathrm{~nm}$. Accordingly it was concluded from Fig. 6 that the species contained equal numbers of Se and $\mathrm{S}$ atoms. Further, given the retention time of the peak, only one of each atom could be present in the parent molecule, presumed to be a selenoamino

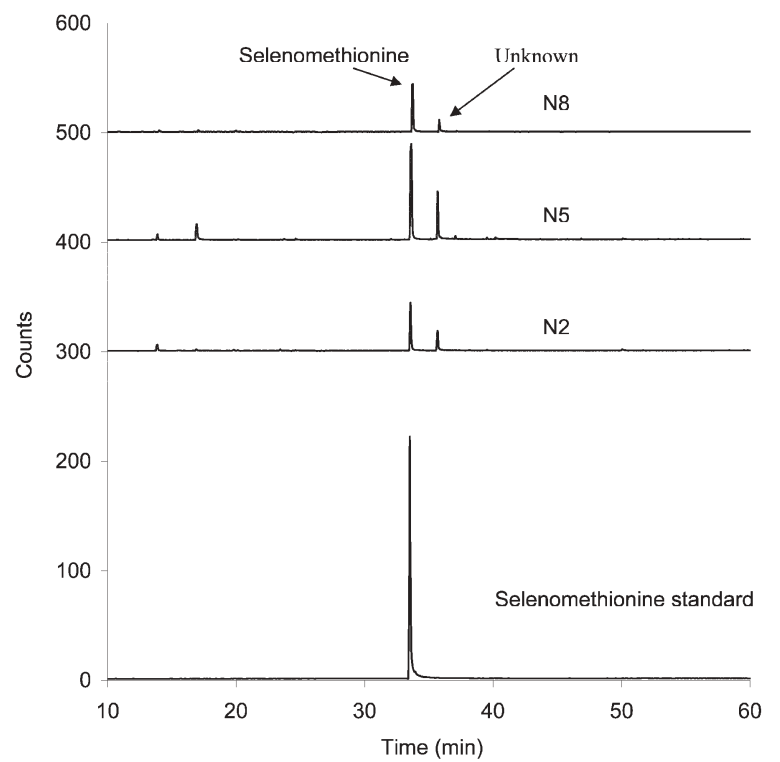

Fig. 5 GC-(Se $196 \mathrm{~nm}$ ) of N2, N5 and N8 Clark yeast tablets using the enzymatic extraction method and derivatization by ethyl chloroformate. Baseline offset for display purposes: N2 trace, baseline is at +300 counts; N 5 trace, baseline is at +400 counts, N8 trace, baseline is at +500 counts. acid. Additional strong evidence for the existence of both $\mathrm{S}$ and $\mathrm{Se}$ in the molecule was gained from spectral examination of the plasma emission present at this peak, the sulfur emission lines at 181,182 and $183 \mathrm{~nm}$ being seen as well as the selenium $196 \mathrm{~nm}$ emission line.

Other evidence was gathered to shed light on the possible nature of this 35 min peak, which was conjectured at this stage to be produced by derivatization of the peak denoted U2 in the liquid chromatograms. Thus, treatment of the Clark yeast extract with $50 \mathrm{mM}$ dithiothreitol, a reagent established to cleave $\mathrm{S}-\mathrm{S}$ or $\mathrm{Se}-\mathrm{Se}$ bonds, removed the $35 \mathrm{~min}$ peak from the GC-AED chromatogram while leaving the derivatized selenomethionine peak untouched. A similar experiment performed using HPLC-ICP-MS analysis gave the same result. Additionally the U2 peak was carefully trapped from the HPLC column for a number of injections and concentrated by freeze-drying. After derivatization this fraction also showed the 35 min peak in $\mathrm{S}$ and Se channels by GC-AED (Fig. 7).

Evidence was now growing that U2 was an amino acid containing a Se-S bond. Such was the low level of the species present and the preponderance of other co-eluting nonselenium species in the HPLC present in the proteolytically extracted yeast that direct HPLC-mass spectrometry proved to be impossible with the available instrumentation. Accordingly, the ethylated derivative was examined by gas chromatographymass spectrometry.

Fig. 8 shows the total ion chromatogram of the derivatized extract and the mass spectrum obtained at the peak eluted at a

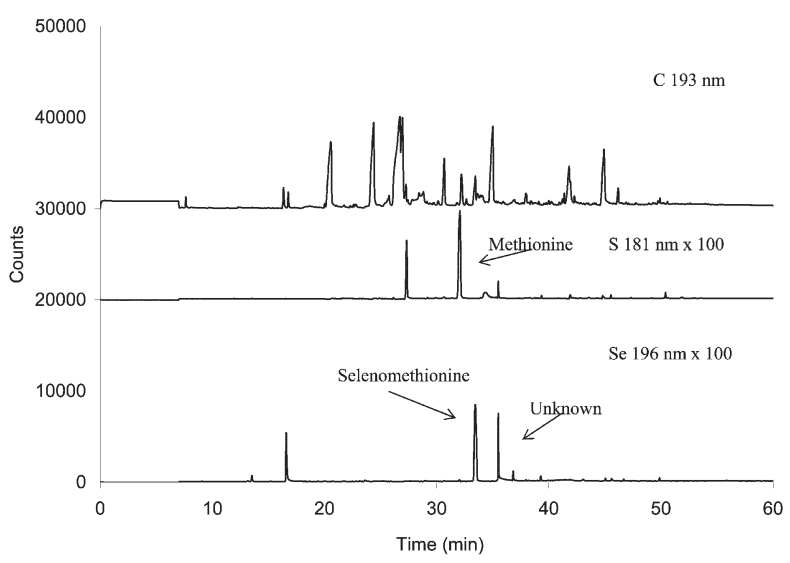

Fig. 6 GC-AED chromatogram of derivatized Clark yeast using the enzymatic extraction and treatment with ethyl chloroformate.

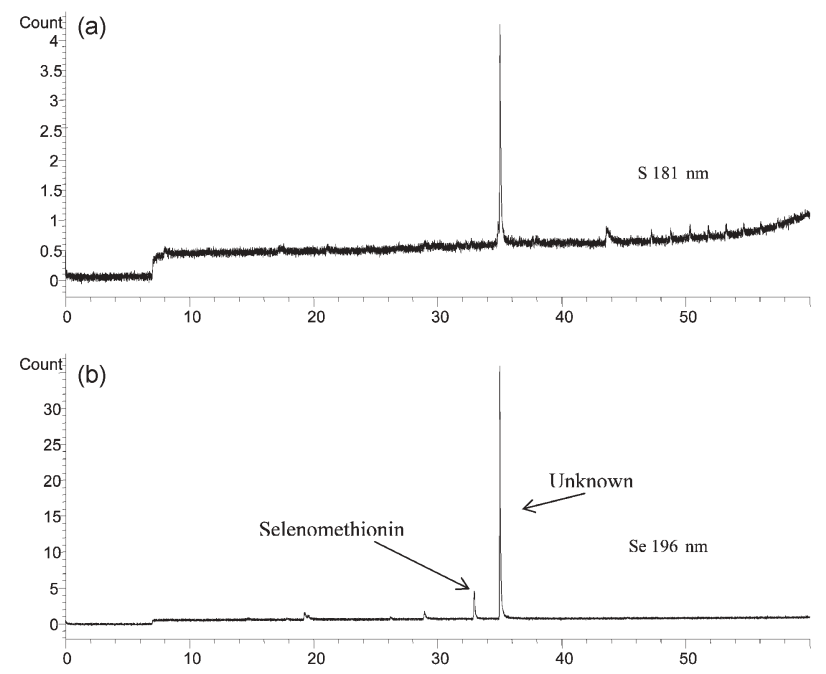

Fig. 7 GC-AED (Se $196 \mathrm{~nm}$ and S $181 \mathrm{~nm}$ ) of trapped fraction collected from HPLC of Unknown 2, derivatized by ethyl chloroformate. 
retention time corresponding to the 35 min peak in GCAED. The main features of the spectrum were readily interpreted as follows. The molecular ion peak $\left(\mathrm{M}^{+}\right)$is seen at $\mathrm{m} / \mathrm{z} 315\left({ }^{80} \mathrm{Se}\right)$ and it also showed the selenium isotope pattern. The cluster of ions at $\mathrm{m} / \mathrm{z} 242$ suggests the selenium isotope pattern and loss of $\mathrm{COOCH}_{2} \mathrm{CH}_{3}(\mathrm{~m} / z$ 73) from the molecular ion $\left(\mathrm{M}^{+}\right)$. The prominent ion at $\mathrm{m} / z 220$ indicates the loss of $\mathrm{SeCH}_{3}(\mathrm{~m} / z$ 95) and shows no selenium isotope pattern. The ion at $m / z 188$ may be interpreted as the loss of $\mathrm{SSeCH}_{3}$ $(m / z 127)$ and that at $m / z 174$ as due to the loss of $\mathrm{CH}_{2} \mathrm{SSeCH}_{3}$ $(\mathrm{m} / \mathrm{z}$ 141). This spectrum gives a strong indication that the U2 molecule contained the $\mathrm{CH}_{2} \mathrm{SSeCH}_{3}$ moiety and was also an amino acid. The conjectured acid is thus $S$-(selenomethyl)cysteine, $\mathrm{CH}_{3} \mathrm{SeSCH}_{2} \mathrm{CH}\left(\mathrm{NH}_{2}\right) \mathrm{COOH}$, a previously unreported species.

While it was considered that there was good evidence for this assignment, the independent synthesis of this molecule was accomplished and will be reported elsewhere. ${ }^{40}$ This synthetic sample was derivatized by the standard method and showed the GC-MS characteristics in Fig. 9. In this spectrum, the principal features are much simpler to observe since the ion background is much lower. The principal ions at $\mathrm{m} / \mathrm{z} 315,242,220,188$ and 174 appear clearly. There are possible assignments based upon apparent selenium isotope patterns of fragments $\mathrm{CH}_{2} \mathrm{SSeCH}_{3}$ $\left(\mathrm{m} / \mathrm{z}\right.$ 141) and $\mathrm{SeCH}_{3}(\mathrm{~m} / \mathrm{z}$ 95). There is a direct correspondence with the $\mathrm{U} 2$ derivative and it is considered that the evidence of identification is conclusive.

\section{Conclusion}

High-selenium yeast in both free yeast and tableted forms, stored at room temperature for more than ten years, gives rise, after subjection to proteolytic digestion and extraction, to substantial amounts of selenomethionine selenoxide hydrate and the previously unreported selenoamino acid $S$-(selenomethyl)cysteine. These observations have important nutritional and perhaps

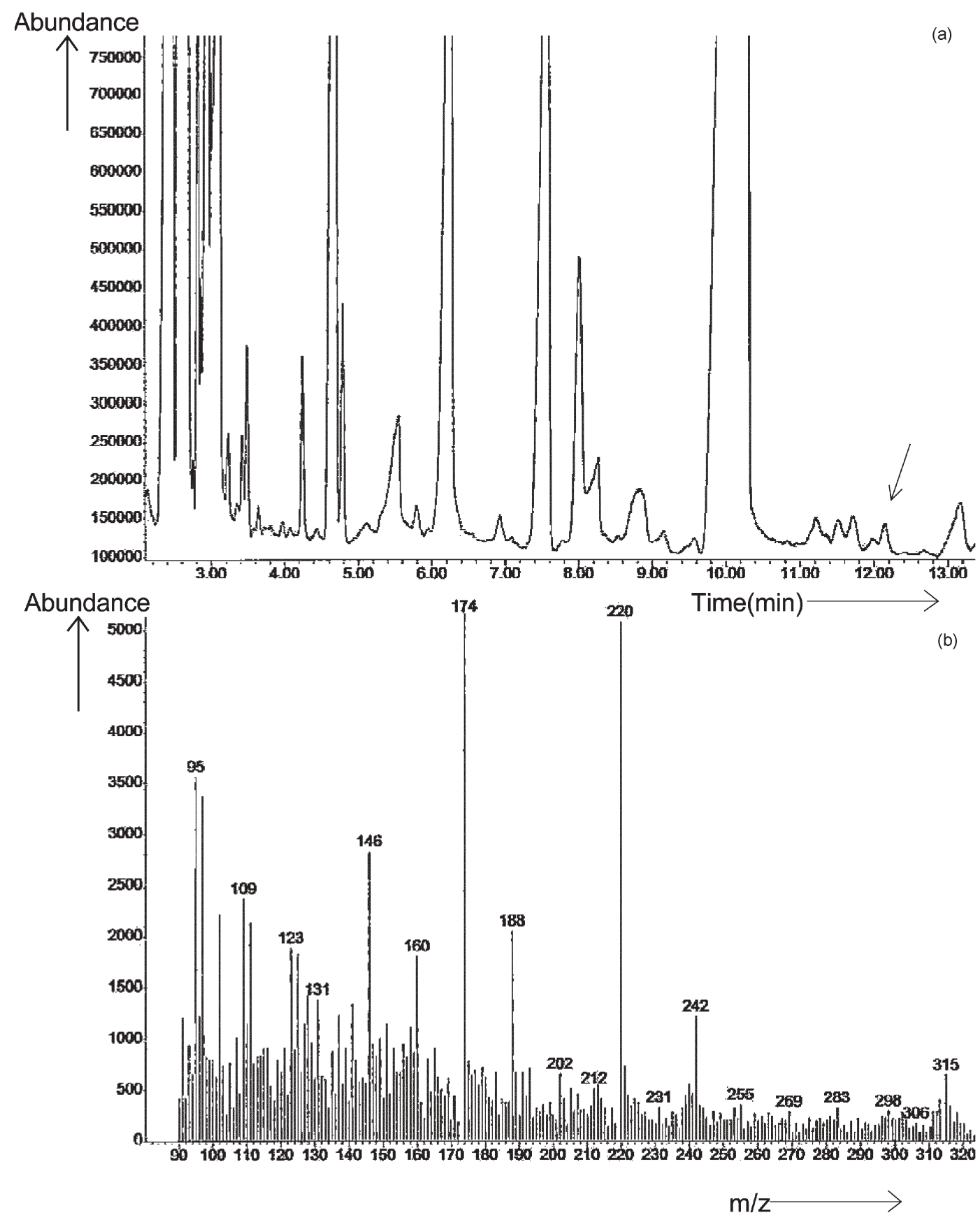

Fig. 8 (a) GC-MS total ion chromatogram of Clark yeast using the extraction method and derivatized by ethyl chloroformate; (b) mass spectrum of the unknown peak U2 in Clark yeast, molecular ion $\mathrm{m} / \mathrm{z}=315\left({ }^{80} \mathrm{Se}\right)$. 


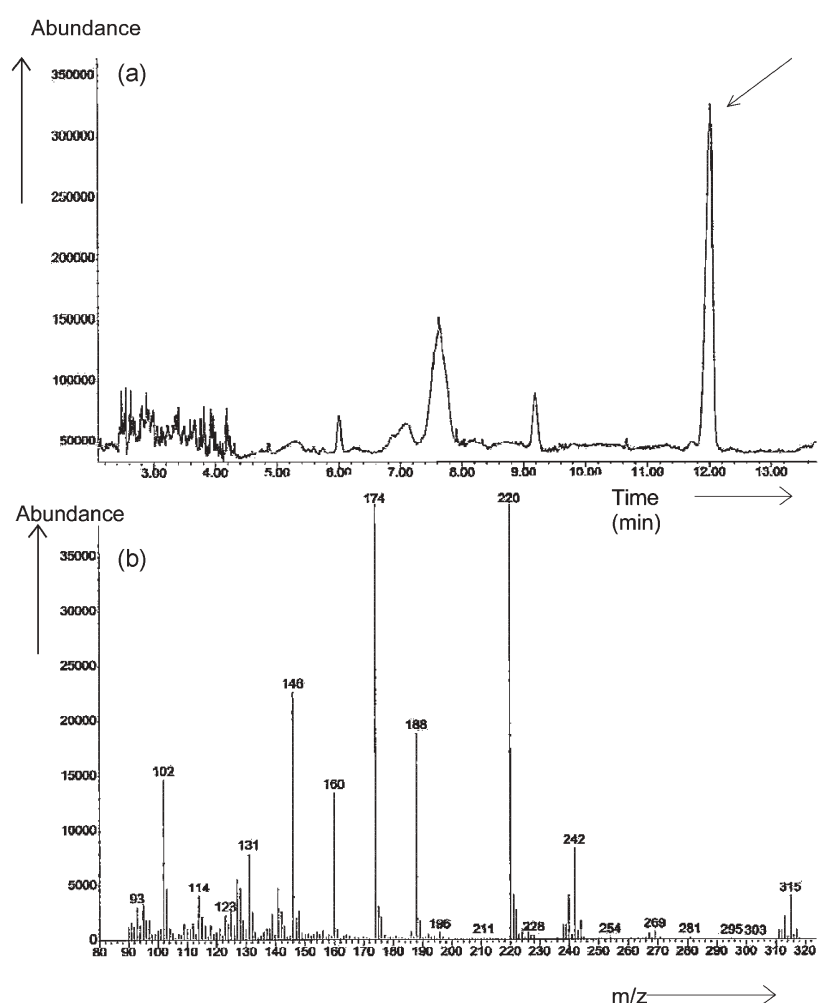

Fig. 9 (a) GC-MS total ion chromatogram of synthesized U2, derivatized by ethyl chloroformate; (b) mass spectrum of selenomethylcysteine, molecular ion $m / z=315\left({ }^{80} \mathrm{Se}\right)$.

metabolic implications. The species now identified as selenomethionine selenoxide hydrate is also observed in smaller proportions for some contemporary selenized yeasts and it is reasonable to conclude that oxidation of selenomethionine in the presence of water contributes variously to this finding in different samples. From the standpoint of nutritional efficacy and selenium uptake, it is possible that the selenoxide is equivalent in action to selenomethionine and is metabolized in the same way. The inclusion of the selenoxide in quantitative measurement of selenomethionine content for selenized yeast seems reasonable. The existence of $S$-(selenomethyl)cysteine has broader import that will be examined further. Perhaps the presence of this $\mathrm{Se}-\mathrm{S}$ species may be related to as yet undefined selenium metabolism. It is not known if speciation changes can occur over the shorter time that the product might be held in storage, but closer examination of other current yeast products suggests that a previously unidentified component present at low concentrations may be $S$-(selenomethyl)cysteine. Studies using the Se-fingerprint method to evaluate the effects of accelerated aging (i.e., high-temperature exposure) on the pattern of Se-compounds in selenized yeast are clearly important. Combs et al. ${ }^{41}$ recently reported the direct measurement of the hitherto unrecognized fraction of plasma containing low molecular weight $(<5 \mathrm{kD}) \mathrm{Se}$ compounds. This is an important finding; inasmuch as it indicates the presence in plasma of one or more Se-species that, if they can be characterized, may offer new and more informative ways to assess Se metabolic status.

\section{Acknowledgements}

This material is based upon work supported by the National Science Foundation under Grants No. 0094568 (J.F.T) and CHE-9906566 (E.B.) and the Petroleum Research Fund, administered by the American Chemical Society (E.B.). Samples and support from Philip Taylor, MD, NIH-NCI, Cypress Systems and McKesson Biosystems are acknowledged.
We thank the PerkinElmer Corporation for provision of the Elan 5000 plasma source mass spectrometer. The provision of $\mathrm{XTerra}^{(}{ }^{\circledR}$ columns by Waters Chromatography Corporation is gratefully acknowledged. The authors also thank Thomas Houle and Mount Holyoke College for providing access to GC-MS instrumentation.

\section{References}

1 O. Wada, N. Kurihara and N. Yamazaki, Jap. J. Nutr. Assess., 1997, 10, 199.

2 H. E. Ganther, Carcinogenesis, 1999, 20(9), 1657.

3 O. A. Levander, Ann. Rev. Nutr., 1987, 7, 227.

4 C. Ip, M. Birringer, E. Block, J. F. Kotrebai, J. F. Tyson, P. C. Uden and D. J. Lisk, J. Agric. Food Chem., 2000, 48, 2062.

5 G. F. Combs and W. P. Gray, Pharmacol. Ther., 1998, 79, 179.

6 H. E. Ganther and J. R. Lawrence, Tetrahedron, 1997, 53, 12229.

7 A. D'Ulivo, Analyst, 1997, 122, 117R.

8 K. Pyrzynska, Analyst, 1996, 121, 77R.

9 R. Lobinski, J. S. Edmonds, K. T. Suzuki and P. C. Uden, Pure Appl. Chem., 2000, 72, 447.

10 P. C. Uden, Anal. Bioanal. Chem., 2002, 373, 422.

11 M. Kotrebai, J. F. Tyson, E. Block and P. C. Uden, J. Chromatog., $2000,866,51$.

12 P. C. Uden, S. M. Bird, M. Kotrebai, P. Nolibos, J. F. Tyson, E. Block and E. R. Denoyer, Fresenius J. Anal. Chem., 1998, 362, 447.

13 N. Jakubowski, D. Stuewer, D. Klockow, C. Thomas and H. J. Emons, J. Anal. At. Spectrom., 2001, 4E.

14 H. Larsen, M. Hansen, T. Fan and M. Vahl, J. Anal. At. Spectrom., 2001, 16, 1403.

15 S. McSheehey, P. Pohl, J. Szpunar, M. Potin-Gautier and R. Lobinski, J. Anal. At. Spectrom., 2001, 16, 68.

16 M. Montes-Bayon, D. L. LeDuc, N. Terry and J. A. Caruso, J. Anal. At. Spectrom., 2002, 17, 872.

17 X.-J. Cai, P. C. Uden, E. Block, X. Zhang, J. J. Sullivan and B. D. Quimby, J. Agric. Food Chem., 1994, 42, 2085.

18 X.-J. Cai, E. Block, P. C. Uden, J. J. Sullivan and B. D. Quimby, J. Agric. Food Chem., 1995, 43, 1751.

19 L. C. Clark, G. F. Combs, B. W. Turnbull, E. H. Slate, D. K. Chalker, J. Chow, L. S. Davis, R. A. Glover, G. F. Graham, E. G. Gross, A. Krongrad, J. L. Lesher, K. Park, B. B. Sanders, C. L. Smith and R. Taylor, J. Am Med. Assoc., 1996, 276, 1957.

20 C. Ip, Z. Chu, H. J. Thompson, D. J. Lisk and H. E. Ganther, Anticancer Res., 1999, 19, 2875.

21 C. Ip, J. Nutr., 1998, 128, 1845.

22 E. A. Klein, I. M. Thompson, S. M. Lippman, P. J. Goodman, D. Albanes, P. R. Taylor and C. Coltman, World J. Urol., 2003 21, 21.

23 K. L. Sutton, C. A. Ponce de Leon, K. L. Ackley, R. M. C. Sutton, A. M. Stalcup and J. A. Caruso, Analyst, 2000, 125, 281.

24 S. McSheehy, F. Pannier, J. Szpunar, M. Potin-Gautier and R. Lobinski, Analyst, 2002, 127, 223.

25 P. Husek, J. Chromatogr., 1991, 552, 289.

26 E. Block, M. Birringer, W. Jiang, T. Nakahodo, H. J. Thompson, P. J. Toscano, H. Uzar, X. Zhang and Z. Zhu, J. Agric. Food Chem., 2001, 49, 458.

27 M. Rooseboom, J. N. Commandeur, G. C. Floor, A. E. Rettie and N. P. Vermeulen, Chem. Res. Toxicol., 2000, 14, 127

28 J. E. Cone, R. M. Del Rio, J. N. Davis and T. C. Stadtman, Proc. Natl. Acad. Sci. USA, 1976, 73, 2659.

29 S. Padjama, G. L. Squadrito, J. N. LeMercier, R. Cueto and W. A. Pryor, Free Rad. Biol. Med., 1996, 21, 317.

30 B. Gammelgaard, C. Cornett, J. Olsen, L. Bendhal and S. H. Hansen, Talanta, 2003, 59, 1165.

31 H. A. Zainal, D. E. Lacroix and W. R. Wolf, Fresenius' J. Anal. Chem., 1996, 355, 311.

32 S. M. Bird, PhD Dissertation, University of Massachusetts, 1998

33 A. A. Isab, Inorg. Chim. Acta, 1983, 80, L3.

34 B. D. Quimby, P. C. Uden and R. M. Barnes, Anal. Chem., 1978, 50, 2112.

35 P. C. Uden, Element-Specific Chromatographic Detection by Atomic Emission Spectroscopy, American Chemical Society Symposium Series \#479, ACS, Washington, DC, 1992.

36 H. Kataoka, Y. Miyanaga and M. Makita, J. Chromatogr. A, 1994, 659, 481. 
37 X.-J. Cai, E. Block, P. C. Uden, X. Zhang, J. J. Sullivan and B. D. Quimby, J. Agric. Food Chem., 1995, 43, 1754.

38 K. Yasumoto, T. Suzuki and M. Yoshida, J. Agric. Food Chem., 1988, 36, 463.

39 P. Nolibos, PhD Dissertation, University of Massachusetts, 2001.

40 E. Block, R. S. Glass, S. Johnson, H. Totoe Boakye,
C. Kahakachchi, J. F. Tyson and P. C. Uden, J. Agric. Food Chem., submitted for publication.

41 G. F. Combs, Jr., T. Hyum and W. P. Gray, in Metal Ions in Biology and Medicine, eds. J. A. Centeno, P. Collery, G. Verney, R. B. Finkelmen, H. Gibb and J. C. Etienne, John Libbey Eurotext, Paris, 2000, pp. 237-240. 